\title{
Could food or food contact surfaces be the favourable hideouts for Listeria monocytogenes in Perak, Malaysia?
}

\author{
${ }^{1}$ Chen, S.N., ${ }^{2}$ Yap, M.L., ${ }^{3}$ Kuan, C.H., ${ }^{4,5}$ Son, R. and ${ }^{1,{ }^{*}}$ Saw, S.H. \\ ${ }^{1}$ Department of Allied Health Sciences, Faculty of Science, Universiti Tunku Abdul Rahman (UTAR), Jalan \\ Universiti Bandar Barat, 31900 Kampar Perak, Malaysia \\ ${ }^{2}$ Department of Biological Science, Faculty of Science, Universiti Tunku Abdul Rahman (UTAR), Jalan \\ Universiti Bandar Barat, 31900 Kampar Perak, Malaysia \\ ${ }^{3}$ Department of Food Science with Nutrition, Faculty of Applied Sciences, UCSI University, Cheras 56000, \\ Kuala Lumpur, Malaysia \\ ${ }^{4}$ Department of Food Science, Faculty of Food Science and Technology, Universiti Putra Malaysia, 43400 \\ Serdang, Selangor, Malaysia \\ ${ }^{5}$ Food Safety and Food Integrity, Institute of Tropical Agriculture and Food Security, Universiti Putra \\ Malaysia, 43400 Serdang, Selangor, Malaysia
}

\begin{abstract}
Article history:
Received: 20 October 2020

Received in revised form: 26

November 2020

Accepted: 5 February 2021

Available Online: 30 May

2021
\end{abstract}

\section{Keywords:}

Listeria,

Contamination,

Safety,

Contact surfaces,

PCR

DOI:

https://doi.org/10.26656/fr.2017.5(3).596

\begin{abstract}
Listeria monocytogenes is a causative agent of foodborne listeriosis which causes a high rate of hospitalisation ( $>90 \%)$ and death $(20-30 \%)$ worldwide. Due to its ubiquitous nature and high resistance to a stressful environment, L. monocytogenes is able to multiply to a threatening level during food processing, distribution and storage, which then causes an immense case of foodborne disease outbreak. Hence, the control of L. monocytogenes is required at all stages in the food chain to prevent its occurrence in the final product. The present study aimed to determine the prevalence of $L$. monocytogenes in food as well as food contact surfaces from food processing plants and food service premises located in Perak, Malaysia. A total number of 170 food samples, including raw, minimally processed, processed and ready-to-eat food, as well as 152 samples from surfaces, including food-contact and non-food-contact, were collected and isolated on culture, and confirmation was done using polymerase chain reaction (PCR). A total of 26 food samples (15.29\%) were positive for L. monocytogenes, with the highest prevalence found in processed and minimally processed food at $33.33 \%$ and $31.25 \%$, respectively; following by raw and ready-to-eat food at $26.32 \%$ and $4.26 \%$ respectively. On the other hand, a higher prevalence of L. monocytogenes was detected from food-contact surfaces at $11.83 \%$ compared to non-food contact surfaces at $6.78 \%$. These findings demonstrated the potential risk of contamination by L. monocytogenes in food and it might be due to the exposure of the bacteria on food processing surfaces. Thus, regular surveillance and strict assessment should be conducted by the local authorities to ensure the safety of the food consumption for residents in Perak.
\end{abstract}

\section{Introduction}

Listeria monocytogenes is a Gram-positive, nonsporeforming and facultative anaerobic bacteria (Farber and Peterkin, 1991; Liu, 2006). It is the most pathogenic species among the 19 Listeria genus members, to human and a range of other animals (Orsi and Wiedmann, 2016; Dojiad et al., 2018). Compared to other foodborne microbial pathogens such as Salmonella spp., Escherichia coli and Campylobacter jejuni, $L$. monocytogenes causes serious listeriosis foodborne outbreaks worldwide, especially in countries of United States of America, European Union, Australia, Nigeria and Asia (Hernandez-Millian and Payeras-Clfre, 2014; Al-Nabulsi et al., 2015; Effimia, 2015; Ng, 2018; Whitworth, 2018; Smith et al., 2019). Infected individuals, especially the vulnerable group of "YOPI": young, old, pregnant and immune-compromised, can lead to episodes of stillbirths, meningitis, septicaemia, gastroenteritis, fever and ultimately resulting in death (Franciosa et al., 2001; De Cesare et al., 2007; Silk et al., 2012). 
L. monocytogenes is able to adapt to extreme environments, such as surviving in a wide range of $\mathrm{pH}$ condition from 4.5 to 9.5 ; multiplying at low refrigeration temperature as $-1{ }^{\circ} \mathrm{C}$ and remaining viable in high salt condition at $40 \% \mathrm{w} / \mathrm{v}$ (Chasseignaux et al., 2002; Bucrieser et al., 2003; Liu, 2006; Meloni et al., 2009; Al-Nabulsi et al., 2015). Due to its durable characteristics, this extremophile grows easily on various food surfaces and forms biofilm: an aggregation of micro -colonies on the surfaces which enables substrate exchange, dissemination of metabolic products and elimination of toxic end products in order to sustain the growth of the bacteria communities (Donlan, 2001). The microbial biofilms immerse in a self-produced matrix of extracellular material, which consists of a conglomeration of different types of biopolymers known as extracellular polymeric substances (EPS's) (Donlan and Costerton, 2002). These structures enable a formation of strong adhesion of Listeria spp. to the surfaces and play a role in protecting the bacteria from antimicrobials invasion and shearing forces, as well as in tolerating the components of both the innate and adaptive immune response and resists phagocytosis. Thus, biofilms production is an important source of $L$. monocytogenes contamination that can lead to food spoilage or transmission of disease (Lundén et al., 2000).

In Malaysia, several prevalence studies had been reported for the presence of L. monocytogenes in various foods such as meat, chicken offal, beef offal, beef patties, vegetables, salad and ready-to-eat food (Arumugaswamy et al., 1994; Tang et al., 1994; Ponniah et al., 2010; Marian et al., 2012; Wong et al., 2012; Kuan, Goh, Loo et al., 2013; Kuan, Wong, Pui et al., 2013; Marian et al., 2019). Contamination of the food could occur at all stages in the food chain especially at the surfaces of the food processing plant and during the distribution of the end products at the premises. This happened in the year 2015, when our Ministry of Agriculture and Food Industry seized the import of $L$. monocytogenes contaminated apples from Bidart Bros in Bakersfield, California (Malay Mail, 2015). The cause of contamination might be due to the occurrence of crosscontamination of the food in the farm with food contact surfaces of food processing plants or retail premises. Thus, this study aimed to investigate the occurrence of $L$. monocytogenes in food and on food contact surfaces in Perak, Malaysia by the culture-method and duplex-PCR (d-PCR) molecular method.

\section{Materials and methods}

\subsection{Sample collection}

From August 2018 to August 2019, a total number of
322 samples (170 food samples and 152 food contact surface samples) were randomly collected from six food premises, two food processing plants, four hypermarkets, a wet market and a night market in Perak, Malaysia. The types of samples collected are summarised in Table 1.

Table 1. The number of samples (shown in bracket) collected in this study. The types of collected samples consisted of food samples (raw, minimally processed, processed and ready-toeat food) and swab samples from direct and indirect food contact surfaces

\begin{tabular}{ll}
\hline \multicolumn{1}{c}{ Source/Total } & \multicolumn{1}{c}{ Samples Collected } \\
\hline Food (170) & \\
\hline \multirow{2}{*}{ Raw Food (38) } & Vegetables (23), \\
& Fresh meat and seafood (10), \\
& Bean sprouts (5) \\
\hline & Minced meats (2), \\
Minimally Processed & Pre-cut meats (5), \\
Food (33) & Pre-cut fishes (6), \\
& Pre-cut vegetables (18), \\
& Bean curds (2) \\
\hline \multirow{2}{*}{ Processed Food (6) } & Quick-frozen meat products (4) \\
& Vacuum-packed meat products (2) \\
\hline & Sandwiches (13), \\
& Salads (10), \\
Ready-to-eat (RTE) & Fruits (12), \\
Food (93) & Sushi rolls (6), \\
& Desserts (25), \\
& Cooked food (27) \\
\hline
\end{tabular}

Food Contact Surfaces (152)

Working benches for food processing

Food processing machines (19),

Direct Food Contact Cutting boards (7),

Surface (93) Conveyor belts (9)

Food preparation tools (mixing bowl,

Surfaces of food product (11)

Trolleys (2),

Display racks (9),

Rack stands (6),

Indirect Food Contact Racks for intermediate storage (9),

Surface (59) Pallets (5)

Walls of cold storage environment (4),

Cleaning equipment (wiping clothes)

\subsubsection{Food samples}

Food samples were purchased freshly from the hypermarkets, wet market and night market. Food from different categories was picked randomly from different stalls of each sampling site. The raw, minimally processed and processed foods were kept separately in cold storage boxes whereas ready-to-eat foods were kept under room temperature during the transportation back to the laboratory for analysis. 


\subsubsection{Swab samples of food contact surfaces}

Swab samples from food contact surfaces were collected according to the protocol described by Public Health England (2017) with slight modifications. Individually packed sterilised cotton swab was premoistened with sterilised $0.85 \%(\mathrm{w} / \mathrm{v})$ of saline solution (Merck, Germany). Then, a sterilised swab template of size $10 \times 10 \mathrm{~cm}$ was placed on the tested area and was swabbed from left to right, up to down and at diagonal sides for $30 \mathrm{~s}$. Rotation of the swab was performed during the collection process. The swabbed cotton was placed into a labelled tube containing $10 \mathrm{~mL}$ of $0.1 \%(\mathrm{w} /$ v) peptone water (LAB M, United Kingdom). Collected samples were stored in a cold storage box during transportation to the laboratory. The samples isolation was then performed within $24 \mathrm{hrs}$.

\subsection{Pre-enrichment, enrichment and purification steps}

The detection and isolation of L. monocytogenes from the collected food samples was performed based on the procedure described by Kuan, Goh, Loo et al. (2013) and Kuan, Wong, Pui et al. (2013) with slight modifications. In brief, $25 \mathrm{~g}$ of food sample (from section 2.1.1) was placed in a sterile stomacher bag and homogenised with $225 \mathrm{~mL}$ of Listeria Enrichment Broth (LEB) (Merck, Germany) for 2 min using stomacher machine of BagMixer ${ }^{\circledR} 400 \mathrm{P}$ (Interscience, France). The suspension of $250 \mathrm{~mL}$ was then incubated for $4 \mathrm{hrs}$ at $30^{\circ} \mathrm{C}$, before adding the selective supplements agents: acriflavin, $10 \mathrm{mg} / \mathrm{L}$, sodium nalidixate, $40 \mathrm{mg} / \mathrm{L}$, cycloheximide $50 \mathrm{mg} / \mathrm{L}$ (Merck, Germany). Incubation was performed for $44 \mathrm{hrs}$ at $30^{\circ} \mathrm{C}$.

On the other hand, the collected swab sample of food contact surfaces (from section 2.1.2) that had immersed in $0.1 \%(\mathrm{w} / \mathrm{v})$ peptone water was vortex for $3 \mathrm{~min}$. A 1 $\mathrm{mL}$ portion of the suspension was then transferred and homogenised in $9 \mathrm{~mL}$ of LEB and incubated for $4 \mathrm{hrs}$ at $30^{\circ} \mathrm{C}$ before the enrichment supplements were added. The samples were further incubated for $44 \mathrm{hrs}$ at $30^{\circ} \mathrm{C}$.

After $48 \mathrm{hrs}$ of incubation, $0.1 \mathrm{~mL}$ of broth for all samples were spread plated on PALCAM agar (Oxoid, UK) and incubated for another $48 \mathrm{hrs}$ at $30^{\circ} \mathrm{C}$. Five presumptive colonies were picked from each PALCAM agar plate and sub-cultured onto Tryptic Soy Agar (TSA) (Merck, Germany). TSA agar was then incubated for 48 hrs at $30^{\circ} \mathrm{C}$. This step was performed to purify the Listeria colonies before DNA extraction was performed.

\subsection{Extraction of DNA}

The boiled cell method was used to extract the DNA of the presumptive colonies from TSA plates, as described by Kuan et al. (2017). Briefly, one full loop of culture was scrapped from the TSA plate and resuspended in $200 \mu \mathrm{L}$ of sterile distilled water. The suspension was then vortex prior to the boiling step at $100^{\circ} \mathrm{C}$ for 10 mins. The cell was then cooled at $-20^{\circ} \mathrm{C}$ for $10 \mathrm{~min}$ before it was centrifuged at 13,400 $x \mathrm{~g}$ for $3 \mathrm{~min}$. The supernatant was subjected to PCR to identify the Listeria spp. and L. monocytogenes strains.

\subsection{Duplex Polymerase Chain Reaction (d-PCR)}

A total of 1,842 presumptive colonies were isolated and verified using duplex-polymerase chain reaction (dPCR). d-PCR was carried out using two primer pairs: LI1 and U1, sequences as LI1-5' CTC CAT AAA CGT GAT CCT 3' and U1-5' CAG CMG CCG CGG CGG TAA TWC 3'; as well as LM1 and LM2, sequences as LM1-5' CCT AAG ACG CCA ATC GAA 3' and LM25' AAG CGC TTG CAA CTG CTC 3'. The first pair was a genus-specific primer for Listeria spp. which amplified at 16S rRNA gene with the size of $938 \mathrm{bp}$, whereas, the second pair was a species-specific primer for $L$. monocytogenes amplified at $h l y \mathrm{~A}$ gene with the size of $702 \mathrm{bp}$. Both primer pairs were synthesised by Apical Scientific Sdn. Bhd. d-PCR amplification was performed as described by Kuan, Goh, Loo et al. 2013 and Kuan, Wong, Pui et al. (2013) with slight modifications. d-PCR was conducted in a reaction mixture of $25 \mu \mathrm{L}$ which contained $5 \mu \mathrm{L}$ of $5 \mathrm{X}$ PCR buffer, $1.5 \mu \mathrm{L}$ of $25 \mathrm{mM} \mathrm{MgCl}_{2}, 0.2 \mu \mathrm{L}$ of $10 \mathrm{mM}$ deoxynucleoside triphosphate mix, $0.3 \mu \mathrm{L}$ of $1.5 \mathrm{U} \mathrm{Taq}$ DNA Polymerase, $0.5 \mu \mathrm{L}$ of LI1 primer, $0.5 \mu \mathrm{L}$ of U1 primer, $0.5 \mu \mathrm{L}$ of LM1, $0.5 \mu \mathrm{L}$ of LM2, $14.0 \mu \mathrm{L}$ of sterile distilled water and $2.0 \mu \mathrm{L}$ of DNA template (supernatant from the extraction of DNA). All reagents used in the PCR amplification were obtained from Promega (Research Instruments, USA). $L$. monocytogenes ATCC 19115 was used as a positive control for each PCR assay. The PCR conditions used was as such: initial denaturation at $94^{\circ} \mathrm{C}$ for 5 mins, followed by 30 cycles of denaturation at $94^{\circ} \mathrm{C}$ for $30 \mathrm{~s}$, annealing at $53^{\circ} \mathrm{C}$ for $1 \mathrm{~min}$ and extension at $72^{\circ} \mathrm{C}$ for 2 mins, followed by a final extension step at $72^{\circ} \mathrm{C}$ for 7 mins. The thermal cycling reactions were performed using Thermal Cycler (Matrioux, Malaysia). Then, the PCR products were subjected to $1.5 \%$ agarose gel electrophoresis in $0.5 \mathrm{X}$ of Tris-Borate-EDTA (TBE) buffer at $100 \mathrm{~V}$ for $45 \mathrm{~min}$. The gel was then stained with $3 \mathrm{X}$ gel red and visualised under a gel imager (Bio-rad, USA). A 100 bp DNA ladder (Vivantis Technologies, Malaysia) was used as a DNA marker to estimate the size of amplified PCR products. 


\section{Results}

3.1 Detection of Listeria monocytogenes in food and on food contact surfaces

The presence of L. monocytogenes was detected on PALCAM agar plate which exhibited colonies of greygreen colour with a black centre (Figure 1). The genus of Listeria was confirmed via PCR amplification of $16 \mathrm{~S}$ rRNA which yielded $938 \mathrm{bp}$ in size, while the presence of the species was confirmed via amplification of its haemolysin gene that encodes for listeriolysin $O(h l y A)$ gene at 702 bp product (Wong et al., 2012) (Figure 2).

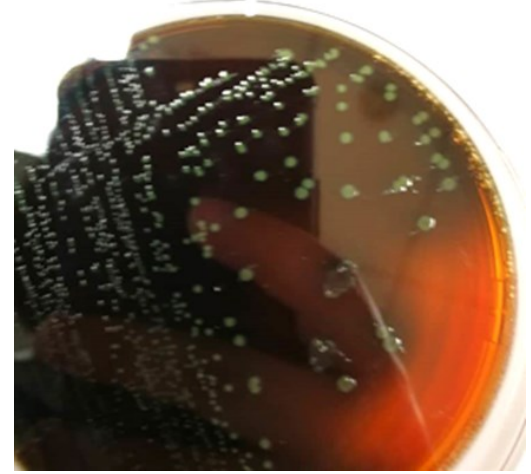

Figure 1. The growth of grey-green coloured colonies with black centre on PALCAM agar exhibited the presence of $L$. monocytogenes

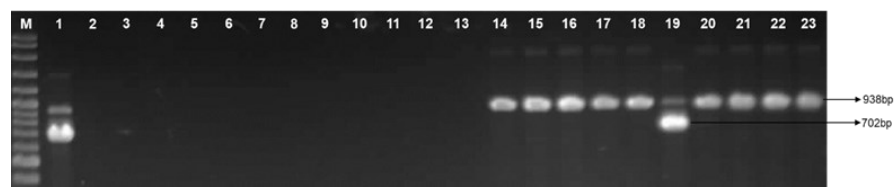

Figure 2. The image of $1.5 \%$ gel electrophoresis showed the PCR amplification of genes 16S rRNA (938 bp) and hlyA (702 bp) for the detection of Listeria spp. and Listeria monocytogenes, respectively. Lane M: 100 bp DNA ladder (Vivantis Technologies, Malaysia); Lane 1: L. monocytogenes ATCC 19115 strain (positive control); Lane 2: Distilled water as template (non-template control); Lane 3 to 13: Listeria spp. negative samples; Lane 14 to 18: Listeria spp. positive samples; Lane 19: L. monocytogenes positive sample; Lane 20 to 23: Listeria spp. positive samples

\subsection{Prevalence of Listeria monocytogenes in food and on food contact surfaces}

Out of 170 food samples collected, 38 (22.35\%) were raw food, $33(19.41 \%)$ were minimally processed food, $6(3.53 \%)$ were processed food and $93(54.71 \%)$ were ready-to-eat food. Among 152 swab samples of contact surfaces collected, $93(61.18 \%)$ were from direct food contact surfaces and $59(38.82 \%)$ were from indirect food contact surfaces (Table 1). The prevalence of Listeria, as well as L. monocytogenes in the food samples and contact surfaces, were tabulated in Table 2. Listeria was found in 69 out of the 322 total samples $(21.42 \%)$ collected and more than half of these samples were positive for L. monocytogenes $(\mathrm{n}=41 / 69,59.42 \%)$.
Among the $26 \mathrm{~L}$. monocytogenes positive food samples, processed food showed the highest prevalence at $33.33 \%$ ( 2 out 6 samples), followed by minimally processed food which accounted for $31.25 \%$ (10 out of 33 samples), raw food at $26.32 \%$ (10 out of 38 samples) and ready-to-eat (RTE) food at 4.26\% (4 out of 93 samples). Nevertheless, Listeria was found in about $18.28 \%$ (17 out of 93 samples) in RTE food, which accounts for some attention on its presence. On the other hand, direct food contact surface was found to be more easily contaminated by $L$. monocytogenes with a prevalence of $11.83 \%$ (11 out of 93 samples) compared to indirect food contact surfaces, where these bacteria were detected at a prevalence of $6.78 \%$ (4 out of 59 samples).

Table 2. The prevalence of Listeria spp. and L. monocytogenes in food and on food contact surfaces.

\begin{tabular}{cccc}
\hline Sources & $\begin{array}{c}\text { No. of } \\
\text { samples }\end{array}$ & $\begin{array}{c}\text { No. (\%) of } \\
\text { Listeria }\end{array}$ & $\begin{array}{c}\text { No. (\%) of } \\
\text { L. monocytogenes }\end{array}$ \\
\hline Foods & 170 & $49(28.82)$ & $26(15.29)$ \\
Raw Food & 38 & $14(36.84)$ & $10(26.32)$ \\
Minimally & 33 & $16(48.48)$ & $10(31.25)$ \\
Processed Food & 6 & $2(33.33)$ & $2(33.33)$ \\
Ready-to-eat Food & 93 & $17(18.28)$ & $4(4.26)$ \\
Food Contact & 152 & $20(13.16)$ & $15(9.87)$ \\
Direct Food Contact & 93 & $14(15.05)$ & $11(11.83)$ \\
Indirect Food & 59 & $6(10.17)$ & $4(6.78)$ \\
Total & 322 & $69(21.43)$ & $41(12.73)$ \\
\hline
\end{tabular}

\section{Discussion}

Listeriosis is a life-threatening foodborne disease that is caused by the ingestion of food contaminated by L. monocytogenes. The questions ponder about the source of the contamination. It is postulated that the bacteria have come in contact at the food processing plant and start multiplying during the storage and at the retail level. In this study, it has been proved that both sources of food and food contact surfaces are at risk of getting exposed to Listeria contamination. Processed food, such as the frozen chicken slices and vacuumpacked smoked duck meat was observed to have the highest prevalence of $L$. monocytogenes, compared to minimally processed food, raw food and RTE food. On the other hand, direct food contact surfaces recorded a higher contamination level of $L$. monocytogenes than indirect food contact surfaces.

Processed food has a higher probability of being contaminated due to its long processing procedures needed. Before turning fresh food into food products, one or a combination of various processes, including washing, chopping, pasteurising, freezing, fermenting, 
packaging and cooking are needed (USDA Agricultural Marketing Service, 2008). Despite the harsh treatment process involved, L. monocytogenes has the ability to strive for survival. Since most of the processed food is stored at low temperature in order to maintain its freshness, it may in turn create a favourable growth condition for the bacteria to proliferate. This observation was supported by a study conducted by Wong et al. (2012) who had reported that $22.33 \%$ of burger patties were detected positive for L. monocytogenes. In Assiut city of Egypt, El-Malek and colleagues (2010) had found a lower prevalence of $L$. monocytogenes detected in frozen meat and chicken samples. In addition, Marian et al. (2012) had reported that $33.3 \%$ of the burger samples collected from local wet markets, mini markets and supermarkets in Selangor, Malaysia were contaminated with L. monocytogenes. Thus, frozen processed meat products are a favourite reservoir for the growth of the foodborne pathogen.

Minimally processed food is another food material that has found to be easily contaminated by $L$. monocytogenes. According to the food classification tool (NOVA classification) developed by Monteiro et al. (2016), minimally processed food, including poultry, meat, seafood steaks, fillets, fresh-cut fruits and vegetables, as well as fresh or dried herbs such as mint or thyme, is a natural food product that undergoes mild processed without the addition of flavouring, salt and sugar. The mild processing steps involve sorting, washing, peeling, slicing, cutting, grinding and removing inedible parts of the fresh produce (Bansal et al., 2015). Again, the surfaces of grinders and some machinery in the process could be the potential sources of Listeria contamination due to the ideal temperature of the production area and improper cleaning of the complicated structure of machinery. In this study, $L$. monocytogenes was found in pre-cut vegetables $(5 / 18)$, pre-cut meats $(2 / 5)$, pre-cut fishes $(2 / 6)$ and bean curds $(1 / 2)$. The results were comparable with the study conducted in Japan and Turkey. Researchers from these two places had found the presence of L. monocytogenes in minced beef $(12.2 \%)$ and ground beef $(7.2 \%)$, as well as chicken meat samples $(17.8 \%)$ from the retail premises (Inoue et al., 2000; Kalender, 2011).

On the other hand, raw food, either animal or plant sources, is natural or unprocessed foods that are obtained directly from farms (Poti et al., 2015; Monteiro et al., 2016). Although the percentage of Listeria spp. in the samples was less than $30 \%$, its presence in 10 out of the 38 samples was a concern of listeriosis threat. Raw food might get contaminated from the soil, wastewater and faeces. Soil treated with artificial fertilizers creates a suitable growth environment for Listeria compared to soil treated with natural fertilizers (Szymczack et al., 2014). On the other hand, improper handling of wastewater management at the farms is often the case for the occurrence of cross-contamination (Lyautey et al., 2007). Thus, proper washing and cooking, preferably at $74^{\circ} \mathrm{C}$ are encouraged to reduce the risk of contracting listeriosis.

In this study, $4.26 \%$ of the RTE food samples derived from fruits (1/12), sandwiches (1/13), desserts $(1 / 25)$ and cooked food $(1 / 27)$ were detected with $L$. monocytogenes. RTE vegetables, fruits and sandwiches are common sources for the sprouting of foodborne pathogens due to their zero heating processes and openshelf storage in low refrigeration temperatures. Ponniah and colleagues (2010) had reported that $22.5 \%$ of RTE vegetables were positive for L. monocytogenes. Also, studies by Jamali et al. (2013), Leong et al. (2014) and Mureddu et al. (2014) had reported the presence of $L$. monocytogenes in RTE food samples at between 5.0 to $30.0 \%$.

Elimination of Listeria poses a great challenge as it has the ability to strive for survival in harsh conditions. Hence, the strategy to mitigate the growth of the pathogen is to first detect the presence of $L$. monocytogenes in food processing plants and food contact surfaces before it reaches the final products. In this study, Listeria was found on the surfaces of the food processing machines such as food processing machines, conveyor belts, working benches for food processing and preparation, as well as on the surfaces of cutting boards. The highest prevalence of $L$. monocytogenes was found in food processing machines (6/19) such as roller bar, orientation and cooling machine. This observation was supported by Lundén et al. (2003), who stated that the complex machines in the processing lines were at high risk to be contaminated by L. monocytogenes due to irregular sanitisation of the food processing surfaces. Also, a low incidence of $L$. monocytogenes was found on the surfaces of processing tools used to produce sausages (Chevallier et al., 2006; Gounadaki et al., 2008). Following these incidences, the researchers in the US had revealed the presence of $L$. monocytogenes in the refrigerated food processing surfaces and equipment despite the regular cleaning and disinfecting (Carpentier and Cerf 2011; Hoelzer et al., 2011). These studies had once again proved the high adaptability of $L$. monocytogenes in harsh environment.

Besides the direct food contact surfaces, non-direct food contact surfaces are a favourable choice for the growth of L. monocytogenes. In the food production area, floor and drains are retained in a cold and wet atmosphere, which create a notably favourable habitat 
for L. monocytogenes to reside. This is seen in this study, whereby Listeria was detected in an area of display racks and cleaning cloths. This was also seen in the study by Leong et al. (2014), who had found a prevalence of $4.4 \%$ of environmental samples collected from 48 food business operators in the Republic of Ireland were positive for $L$. monocytogenes. On the other hand, contamination rate of $L$. monocytogenes on non-food contact surfaces such as floors, walls, drying rooms and steaming rooms in meat processing line were astonishingly high in the range between $11.0 \%$ to $25.0 \%$ (Thévenot et al., 2005; Mureddu et al., 2014).

In this study, the overall prevalence of $L$. monocytogenes detected in foods and on food contact surfaces from the food processing plant and food premises were low. Nevertheless, there is still a need for active surveillance in order to monitor the real scenario and to create awareness on the importance of cleanliness status in food and food contact surfaces from food processing plants and premises.

\section{Conclusion}

In conclusion, the overall prevalence of $L$. monocytogenes in food and food contact surfaces from food processing and food services environment are lower in Perak compared to studies in Selangor, Malaysia. However, this might pose a risk of listeriosis outbreak if further action is not taken as it will act as the route of transmission to the consumers. Food handlers, especially in the food industry and food premises have to perform robust surveillance, risk assessment and practice effective sanitary procedures in order to reduce the risk of growth of L. monocytogenes. It is important that efforts continue to understand the ability of the organism to survive and multiply under adverse conditions, and this knowledge can be used to design new control strategies.

\section{Conflict of interest}

The authors declare no conflict of interest.

\section{Acknowledgements}

The research has been carried out under the Fundamental Research Grant Scheme project FRGS/1/2019/SKK06/UTAR/03/2 provided by the Ministry of Higher Education of Malaysia. We also want to thank Universiti Tunku Abdul Rahman Research Fund project IPSR/RMC/UTARRF/2018-C1/K01 for supporting the study. In addition, we wish to express our sincere gratitude to all food processing industries located in Perak, which had allowed us to do samplings in their domains.

\section{References}

Al-Nabulsi, A.A., Osaili, T.M., Shaker, R.R., Olaimat, A.N., Jaradat, Z.W., Elabedeen, N.A. and Holley, R.A. (2015). Effects of osmotic pressure, acid, or cold stresses on antibiotic susceptibility of Listeria monocytogenes. Food Microbiology, 46, 154-160. https://doi.org/10.1016/j.fm.2014.07.015

Arumugaswamy, R.K., Rahmat Ali, G.R. and Hamid, S.N. (1994). Prevalence of Listeria monocytogenes in foods in Malaysia. International Journal of Food Microbiology, 23(1), 117-121. https:// doi.org/10.1016/0168-1605(94)90227-5

Bansal, V., Siddiqui, M.W. and Rahman, M.S. (2015). Minimally Processed Foods: Overview. In Siddiqui, M. and Rahman, M. (Eds). Minimally Processed Foods. Food Engineering Series, p. 1-15. Switzerland AG: Springer. https:// doi.org/10.1007/978-3-319-10677-9_1

Bucrieser, C. Christophe, R., Kunst, F., Cossart, P. and Glaser, P. (2003). Comparison of the genome sequences of Listeria monocytogenes and Listeria innocua: clues for evolution and pathogenicity. FEMS Immunology and Medical Microbiology, 35 (3), 207-213. https://doi.org/10.1016/S0928-8244 (02)00448-0

Carpentier, B. and Cerf, O. (2011). Review - Persistence of Listeria monocytogenes in food industry equipment and premises. International Journal of Food Microbiology, 145(1), 1-8. https:// doi.org/10.1016/j.ijfoodmicro.2011.01.005

Chasseignaux, E., Gérault, P., Toquin, M.T., Salvat, G., Colin, P. and Emel, G. (2002). Ecology of Listeria monocytogenes in the environment of raw poultry meat and raw pork meat processing plants. FEMS Microbiology Letters, 210(2), 271-275. https:// doi.org/10.1111/j.1574-6968.2002.tb11192.x

Chevallier, I., Ammor, S., Laguet, A., Labayle, S., Castanet, V., Dufour, E. and Talon, R. (2006). Microbial ecology of a small-scale facility producing traditional dry sausage. Food Control, 17(6), 446453. https://doi.org/10.1016/j.foodcont.2005.02.005

De Cesare, A., Mafreda, G., Macri, M. and Cantoni, C. (2007). Application of automated ribotyping to support the evaluation of Listeria monocytogenes sources in a Taleggio cheese producing plant. Journal of Food Protection, 70(5), 1116-1121. https://doi.org/10.4315/0362-028X-70.5.1116

Dojiad, S.P., Poharkar, K.V., Kale, S.B., Kerkar, S., Kalorey, D.R., Kurkure, N.V., Rawool, D.B., Malik, S.V.S., Ahmad, R.Y., Hudel, M., Chaudhari, S.P., Abt, B., Overmann, J., Weigel, M., Hain, T., Barbuddhe, S.B. and Chakraborty, T. (2018). 
Taxonomic description Listeria goaensis sp. nov. International Journal of Systematic and Evolutionary Microbiology, 68(10), 3285-3291. https://doi.org/10.1099/ijsem.0.002980

Donlan, R.M. (2001). Biofilm formation: a clinically relevant microbiological process. Clinical Infectious Diseases, 33(8), 1387-1392. https:// doi.org/10.1086/322972

Donlan, R.M. and Costerton, J.W. (2002). Biofilms: survival mechanisms of clinically relevant microorganisms. Clinical Microbiology Reviews, 15 (2), 167-193. https://doi.org/10.1128/CMR.15.2.167 $-193.2002$

Effimia, E. (2015). Prevalence of Listeria monocytogenes and Salmonella spp. in ready-to-eat foods in Kefalonia, Greece. Journal of Bacteriology and Parasitology, 6(5), 243.

El-Malek, A.M.A., Ali, S.F.H., Hassanein, R., Mohamed, M.A. and Elsayh, K.I. (2010). Occurrence of Listeria species in meat, chicken products and human stools in Assiut city, Egypt with PCR use for rapid identification of Listeria monocytogenes. Veterinary World, 3(8), 353-359. https://doi.org/10.5455/vetworld.2010.353-359

Farber, J.M. and Peterkin, P.I. (1991). Listeria monocytogenes, a food-borne pathogen. Microbiology Reviews, 55(3), 476-511. https:// doi.org/10.1128/MR.55.3.476-511.1991

Franciosa, G., Tartaro, S., Wedell-Neergaard, C. and Aureli, P. (2001). Characterization of Listeria monocytogenes strains involved in invasive and noninvasive listeriosis outbreaks by PCR-based fingerprinting techniques. Applied and Environmental Microbiology, 67(4), 1793-1799. https://doi.org/10.1128/AEM.67.4.1793-1799.2001

Gounadaki, A.S., Skandamis, P.N., Drosinos, E.H. and Nyhas, G.E. (2008). Microbial ecology of food contact surfaces and products of small-scale facilities producing traditional sausages. Food Microbiology, 25(2), 313-323. https://doi.org/10.1016/ j.fm.2007.10.001

Hernandez-Milian, A. and Payeras-Cifre, A. (2014). What is new in Listeriosis? BioMed Research International, 2014, 358051. https:// doi.org/10.1155/2014/358051

Hoelzer, K., Sauders, B.D., Sanchez, M.D., Olsen, P.T., Pickett, M.M., Mangione, K.J., Rice, D.H., Corby, J., Stich, S., Fortes, E.D., Roof, S.E., Grohn, Y.T., Wiedmann, M. and Oliver, H.F. (2011). Prevalence, distribution, and diversity of Listeria monocytogenes in retail environments, focusing on small establishments and establishments with a history of failed inspections. Journal of Food Protection, 74 (7), 1083-1095. https://doi.org/10.4315/0362028X.JFP-10-567

Inoue, S., Nakama, A., Arai, Y., Kokubo, Y., Maruyama, T., Saito, A., Yoshida, T., Terao, M., Yamamoto, S. and Kumagai, S. (2000). Prevalence and contamination levels of Listeria monocytogenes in retail foods in Japan. International Journal of Food Microbiology, 59(1-2), 73-77. https:// doi.org/10.1016/S0168-1605(00)00284-1

Jamali, H., Chai, L.C. and Thong, K.L. (2013). Detection and isolation of Listeria spp. and Listeria monocytogenes in ready-to-eat foods with various selective culture media. Food Control, 32(1), 19-24. https://doi.org/10.1016/j.foodcont.2012.11.033

Kalender, H. (2011). Prevalence of Listeria species in ground beef and chicken meat sold in Eastern Turkey. Pakistan Veterinary Journal, 32(3), 456458.

Kuan, C.H., Goh, S.G., Loo, Y.Y., Chang, W.S., Lye, Y.L., Soopna, P., Tang, J.Y.H., Nakaguchi, Y., Nishibuchi, M., Mahyudin, N.A. and Radu, S. (2013). Prevalence and quantification of Listeria monocytogenes in chicken offal at the retail level in Malaysia. Poultry Science, 92(6), 1664-1669. https:// doi.org/10.3382/ps.2012-02974

Kuan, C.H., Rukayadi, Y., Ahmad, S.H., Wan Mohamed Radzi, C.W.J., Kuan, C.S., Yeo, S.K., Thung, T.Y., New, C.Y., Chang, W.S., Loo, Y.Y., Tan, C.W., Ramzi, O.S.B., Mohd Fadzil, S.N., Nordin, Y., Kwan, S.Y. and Radu, S. (2017). Antimicrobial resistance of Listeria monocytogenes and Salmonella Enteritidis isolated from vegetables farms and retail markets in Malaysia. International Food Research Journal, 24(4), 1831-1839.

Kuan, C.H., Wong, W.C., Pui, C.F., Tang, J.Y.H., Nishibuchi, M., Mahyudin, N.A. and Radu, S. (2013). Prevalence and quantification of Listeria monocytogenes in beef offal at retail level in Selangor, Malaysia. Brazilian Journal of Microbiology, 44(4), 1169-1172. https:// doi.org/10.1590/S1517-83822014005000002

Leong, D., Alvarez-Ordóñez, A. and Jordan, K. (2014). Monitoring occurrence and persistence of Listeria monocytogenes in foods and food processing environments in the Republic of Ireland. Frontiers in Microbiology, 5, 436. https://doi.org/10.3389/ fmicb.2014.00436

Liu, D. (2006). Identification, subtyping and virulence determination of Listeria monocytogenes, an important foodborne pathogen. Journal of Medical Microbiology, 55(6), 645-659. https:// doi.org/10.1099/jmm.0.46495-0 
Lundén, J.M., Autio, T.J., Sjöberg, A.M. and Korkeala, H.J. (2003). Persistent and non-persistent Listeria monocytogenes contamination in meat and poultry processing plant. Journal of Food Protection, 66 (11), 2062-2069. https://doi.org/10.4315/0362-028X66.11 .2062

Lundén, J.M., Miettinen, M.K., Autio, T.J. and Korkeala, H.J. (2000). Persistent Listeria monocytogenes strains show enhanced adherence to food contact surface after short contact times. Journal of Food Protection, 63(9), 1204-1207. https:// doi.org/10.4315/0362-028X-63.9.1204

Lyautey, E., Hartamann, A., Pagotto, F., Tyler, K., Lapen, D.R., Wilkes, G., Piveteau, P., Rieu, A., Robertson, W.J., Medeiros, D.T., Edge, T.A., Gannon, V. and Topp, E. (2007). Distribution and characteristics of Listeria monocytogenes isolates from surface waters of south nation river watershed, Ontario, Canada. Applied Environment Microbiology, 73(5), 401-410. https:// doi.org/10.1128/AEM.00354-07

Malay Mail (2015). Listeriosis: Identifying A Potential Killer. Mediaworks Malaysia., p.1.

Marian, A.R., Ismail, M., Nurilyana, M.T., Mohd Fharok, Y. and Azzura, A.L. (2019). Incidence of Listeria monocytogenes in dairy and food products of animal origin in central region of Peninsular Malaysia. Malaysian Journal of Veterinary Research, 10(2), 106-112.

Marian, M.N., Sharifah Aminah, S.M., Zuraini, M.I., Radu, S., Maimunah, M., Lee, H.Y., Wong, W.C. and Elexson, N. (2012). MPN-PCR detection and antimicrobial resistance of Listeria monocytogenes isolated from raw and ready-to-eat foods in Malaysia. Food Control, 28(2), 309-314. https:// doi.org/10.1016/j.foodcont.2012.05.030

Meloni, D., Galluzzo, P., Mureddu, A., Piras, F., Griffiths, M. and Mazzette, R. (2009). Listeria monocytogenes in RTE Foods Marketed in Italy: Prevalence and Automated EcoRI Ribotyping of the Isolates. International Journal of Food Microbiology, 129(2), 166-173. https:// doi.org/10.1016/j.ijfoodmicro.2008.11.014

Monteiro, C.A., Cannon, G., Levy, R. Moubarac, J., Jaime, P., Martins, A.P., Canella, D., Louzada, M., Parra, D., Ricardo, C., Calixto, G., Machado, P., Martins, C., Martinez, E., Baraldi, L., Garzillo, J. and Sattamini, I. (2016). Food classification. Public health NOVA. The star shines bright. World Nutrition, 7(1-3), 28-38.

Mureddu, A., Mazza, R., Fois, F., Meloni, D., Bacciu, R., Piras, F. and Mazzette, R. (2014). Listeria monocytogenes persistence in ready-to-eat sausages and in processing plants. Italian Journal of Food Safety, 3(1), 1697. https://doi.org/10.4081/ ijfs.2014.1697

Ng, H.W. (2018). 2 Singapore Patients Infected by Listeria Bacteria Strain Similar to Australia Outbreak: MOH. Retrieved on May 17, 2020 from website: https://www.straitstimes.com/singapore/ health/2-singapore-patients-found-to-be-infected-bylisteria-bacteria-strain-similar-to

Orsi, R.H. and Wiedmann, M. (2016). Characteristics and distribution of Listeria spp., including Listeria species newly described Since 2009. Applied Microbiology and Biotechnology, 100(12), 52735287. https://doi.org/10.1007/s00253-016-7552-2

Ponniah, J., Robin, T., Paie, M.S., Radu, S., Ghazali, F.M., Kqueen, C.Y., Nishibuchi, M., Nakaguchi, Y. and Malakar, P.K. (2010). Listeria monocytogenes in raw salad vegetables sold at retail level in Malaysia. Food Control, 21(5), 774-778. https:// doi.org/10.1016/j.foodcont.2009.09.008

Poti, J.M., Mendez, M.A., Ng, S.W. and Popkin, B.M. (2015). Is the degree of food processing and convenience linked with the nutritional quality of foods purchased by US households? The American Journal of Clinical Nutrition, 101(6), 1251-1262. https://doi.org/10.3945/ajcn.114.100925

Public Health England. (2017). Detection and Enumeration of Bacteria in Swabs and Other Environmental Samples. National Infection Service Food Water and Environmental Microbiology Standard Method. Retrieved on April 5, 2020 from website: https://assets.publishing.service.gov.uk/ government/uploads/system/uploads/ attachment_data/file/660648/

Detection_and_enumeration_of_bacteria_in_swabs and_other_environmental_samples.pdf

Silk, B.J., Date, K.A., Jackson, K.A., Pouillot, R., Holt, K.G., Graves, L.M., Ong, K.L., Hurd, S., Meyer, R., Marcus, R., Shiferaw, B., Norton, D.M., Medus, C., Zansky, S.M., Cronquist, A.B., Henao, O.L., Jones, T.F., Vugia, D.J., Farley, M.M. and Mahon, B.E. (2012). Invasive listeriosis in the foodborne diseases active surveillance network (FoodNet), 2004-2009: Further targeted prevention needed for higher-risk groups. Clinical Infectious Diseases, 54(5), 396-404. https://doi.org/10.1093/cid/cis268

Smith, A.M., Tau, N.P., Smouse, S.L., Ismail, A., Ramalwa, N.R., Disenyeng, B., Ngomane, M. and Thomas, J. (2019). Outbreak of Listeria monocytogenes in South Africa, 2017-2018: Laboratory activities and experiences associated with whole-genome sequencing analysis of isolates. Foodborne Pathogens and Disease, 16(7), 524-530. 
https://doi.org/10.1089/fpd.2018.2586

Szymczack, B., Szymczak, M., Sawicki, W. and Dabrowski, W. (2014). Anthropogenic impact on the presence of Listeria monocytogenes in soil, fruits, and vegetables. Folia Microbiologica, 59(1), 23-29. https://doi.org/10.1007/s12223-013-0260-8

Tang, M.Y., Cheong, Y.M. and Zainuldin, T. (1994). Incidence of Listeria spp. in vegetables in Kuala Lumpur. Medical Journal of Malaysia, 49(3), 217222.

Thévenot, D., Delignette-Muller, M., Christieans, S. and Vernozy-Rozand, C. (2005). Prevalence of Listeria Monocytogenes in 13 dried sausage processing plants and their products. International Journal of Food Microbiology, 102(1), 85-94. https:// doi.org/10.1016/j.ijfoodmicro.2004.12.008

USDA Agricultural Marketing Service. (2008). Country of Origin Labelling (COOL) Frequently Asked Questions. Retrieved on April 20, 2020 from website: https://www.ams.usda.gov/sites/default/ files/media/FAQs\%20for\%20Consumers\%20-\% 20English.pdf

Whitworth, J. (2018). South Africa Declares End to Largest Ever Listeria Outbreak. Retrieved on May 10, 2020 from Food Safety News website: https:// www.foodsafetynews.com/2018/09/south-africadeclares-end-to-largest-ever-listeria-outbreak/ \#: : text $=$ The $\% 20$ largest $\% 20$ ever $\% 20$ detected $\%$ 20Listeria,of\%20listeriosis\%2C\%20including\% 20216\%20deaths.

Wong, W.C., Pui, C.F., Tunung, R., Cheah, Y.K., Nakaguchi, Y., Nishibuchi, M. and Radu, S. (2012). Prevalence of Listeria monocytogenes in frozen burger patties in Malaysia. International Food Research Journal, 19(4), 1751-1756. 